This item was submitted to Loughborough's Research Repository by the author.

Items in Figshare are protected by copyright, with all rights reserved, unless otherwise indicated.

\title{
Design of structures by a splitting method
}

PLEASE CITE THE PUBLISHED VERSION

http://dx.doi.org/10.1016/S0045-7949(98)00176-X

PUBLISHER

(c) Elsevier

VERSION

AM (Accepted Manuscript)

LICENCE

CC BY-NC-ND 4.0

REPOSITORY RECORD

Watson, Andrew, David Kennedy, and F.W. Williams. 2011. "Design of Structures by a Splitting Method". figshare. https://hdl.handle.net/2134/8701. 
This item was submitted to Loughborough's Institutional Repository (https://dspace.lboro.ac.uk/) by the author and is made available under the following Creative Commons Licence conditions.

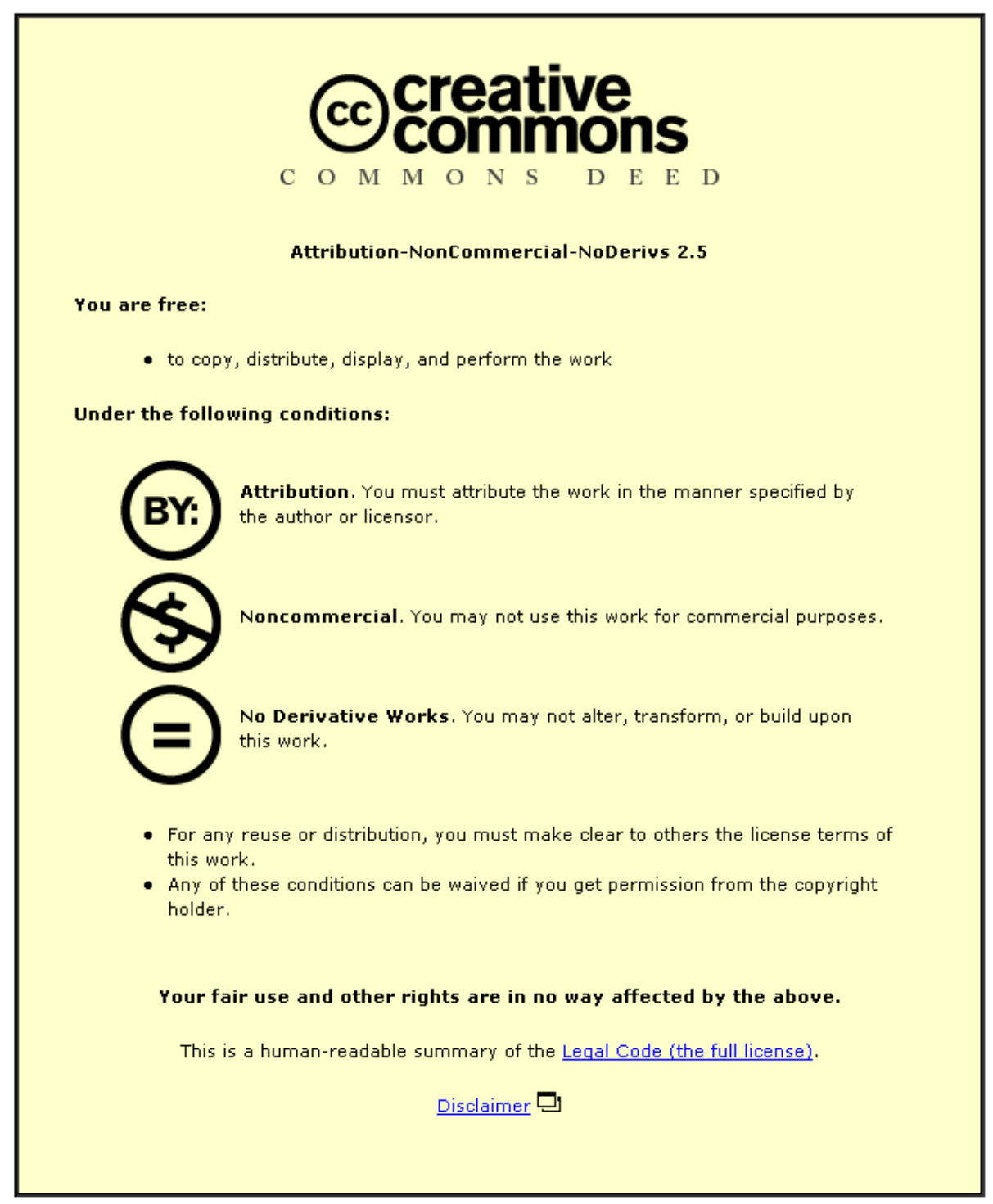

For the full text of this licence, please go to: http://creativecommons.org/licenses/by-nc-nd/2.5/ 


\title{
DESIGN OF STRUCTURES BY A SPLITTING METHOD
}

\author{
A. Watson* ${ }^{*}$ D. Kennedy $\$$ and F.W. Williams $\dagger$ \\ * Research Student, Cardiff School of Engineering, Queen's Buildings, The Parade, \\ P.O. Box 686, Cardiff CF2 3TB \\ \$ Lecturer, Cardiff School of Engineering, Queen's Buildings, The Parade, P.O. Box \\ 686, Cardiff CF2 3TB \\ $\dagger$ Professor, Head of Division of Structural Engineering, Cardiff School of \\ Engineering, Queen's Buildings, The Parade, P.O. Box 686, Cardiff CF2 3TB
}

\begin{abstract}
A simplified method for the design of multi-spar wing boxes is presented. In typical multi-spar wing boxes the spars divide the boxes into cells. In the method presented these are analyzed individually, with adjacent cells taking their share of the stiffnesses of the common spar wall. This splitting method yields a design method that is computationally much quicker than designing a complete wing box, because each cell is considered separately from the others, except for linking between their design variables. The critical buckling load factor of the assembled structure when designed in this way will usually exceed the design load factor and otherwise will be equal to it, i.e. the design is guaranteed to be conservative.
\end{abstract}

\section{INTRODUCTION}

There is a move towards the use of composite material in civil aircraft because overall operating costs mean that fabrication costs can be offset and because 
composite materials are well established for fighter aircraft. 'Next generation' wing boxes are typically tending towards composite structures. The design of wing boxes can be very time consuming and involves considering various factors, one of which is buckling of the skin.

There is a voluminous literature on simple but approximate methods for analyzing such structures, e.g. hand methods using data sheets. They can also be analyzed by many finite element codes, but this is very computationally intensive, particularly if high accuracy is required because then the elements must be very small and hence numerous, e.g. to model local buckling sufficiently accurately. Therefore several authors have produced either approximate (i.e. finite) strip or exact strip methods to analyze such structures much (e.g. 2 or 3 orders) faster than finite elements can, e.g. see refs. [1-8]. However very few finite strip papers, e.g. refs. [912], cover design for buckling (or vibration) as well as analysis.

The computer program VICONOPT is able to design any prismatic assembly of isotropic or anisotropic plates [13]. Hence it can be used to design complete wing boxes. It does so by exact analysis when the plates are isotropic or orthotropic and carry no in-plane shear loads and otherwise gives a very close approximation. It is probably the fastest code available for this purpose and is usually between 100 and 1000 times quicker than a design using finite elements. Nevertheless, even faster methods are desirable, particularly for preliminary design.

A faster simplified method, which is approximate but guaranteed to give conservative designs, is to design the structure by dividing it into cells which are then designed individually except for linking between their design variables, see Figure 1 which is discussed in more detail later. This is done by the code VMULTI, which has 
been fully implemented as an option in the latest release of the code VICONOPT (VIPASA [14] with CONstraints and OPTimization).

VICONOPT is a FORTRAN 77 computer program which incorporates the earlier programs VIPASA (Vibration and Instability of Plate Assemblies including Shear and Anisotropy) and VICON [15] (VIPASA with CONstraints). It covers any prismatic assembly of isotropic, orthotropic or anisotropic plates each of which can carry any combination of longitudinally invariant in-plane stresses. It can be used as either an analysis or an optimum design program. Its VIPASA and VICON analysis options are both used in this paper to calculate the eigenvalues, i.e. the critical load factors because the problems of this paper involve buckling, although in the code the eigenvalues can alternatively be the natural frequencies of undamped vibration. The VICON method is used for overall modes and the VIPASA method is used for shorter wavelength modes. The VICON method can be used to solve any analysis problem which could otherwise be solved by VIPASA, but has substantial additional capability, e.g. it models end conditions much more accurately for overall modes of plate assemblies with substantial in-plane shear loads, for which VIPASA is very conservative. This is because VIPASA assumes modes having a sinusoidal longitudinal variation with half-wavelength $\lambda$, whereas VICON modes are sums of such modes obtained by coupling different values of $\lambda$, as follows.

\section{NECESSARY INFORMATION ABOUT VICONOPT}

The VICON option of VICONOPT assumes an infinitely long plate assembly and uses Lagrangian multipliers to couple the responses for an appropriate set of half- 
wavelengths, $\lambda$, so as to satisfy point support conditions which repeat at longitudinal intervals of $l$. Thus a plate assembly of finite length $l$ with simply supported ends may be modelled reasonably accurately by representing the simple supports by a transverse line of rigid point supports at $\mathrm{x}=0$. The results assume that the mode repeats over a length $\mathrm{L}=2 l / \xi$ for some value $0 \leq \xi, \leq 1$. Each value of $\xi$ generates an infinite series of $\lambda$, although in practice the series is truncated by choosing a value of q in eqn (1) such that acceptable results are obtained.

$$
\lambda_{\mathrm{m}}=l /(\xi+2 \mathrm{~m}) \quad\left\{\begin{array}{l}
\mathrm{m}=0,1,2, \ldots \ldots,(\mathrm{q}-1) \text { for } \xi=0 \text { or } 1 \\
\mathrm{~m}=0, \pm 1 \pm 2, \ldots . \pm \mathrm{q} \text { otherwise }
\end{array}\right\}(1)
$$

Table 1 lists the values of $\lambda$ derived from eqn (1) for typical values of $\xi$ and Figure 2 shows the Hermitian overall matrix used by VICONOPT when four values of $\lambda$ are coupled by the VICON option. Negative values of $\lambda_{m}$ indicate that the complex conjugate of the Hermitian stiffness matrix $\mathbf{K}_{\mathrm{m}}$ must be used. The (approximately) triangular shape of the constraint matrices, $\mathbf{e}_{\mathrm{m}}$, is achieved by ordering the point supports in ascending order of the node numbers (also used when assembling the $\mathbf{K}_{\mathrm{m}}$ ) of the nodes at which they are attached. This triangular shape makes the calculations faster. The number of eigenvalues exceeded by an initial trial value is given by

$$
\mathbf{J}=\sum_{\mathrm{m}}\left(\mathrm{J}_{0 \mathrm{~m}}+\mathrm{s}\left\{\mathbf{K}_{\mathrm{m}}\right\}\right)+\mathrm{s}\{\mathbf{R}\}-\mathrm{r}
$$

where $\mathbf{J}_{0 \mathrm{~m}}$ is the number of eigenvalues which would be exceeded if all of the degrees of freedom at junctions (i.e. nodes) between the plates of the assembly were to be clamped and $s\{\}$ is the sign count of the matrix within the brackets, i.e. the number of negative elements on its leading diagonal after it has been reduced to upper triangular 
form by the usual form of Gaussian elimination, in which multiples of the pivotal row are added to (unscaled) succeeding rows. Here $r$ is the number of point supports and so is also the order of the matrix $\mathbf{R}$, which replaces the null matrix of Figure 2 when Gauss elimination is applied to the complete matrix of Figure 2 and is arrested after all rows except those in $\mathbf{R}$ have been pivotal. For analysis problems, convergence on the buckling load factor is achieved by calculating $\mathrm{J}$ at appropriately chosen successive values of the load factor. Design involves a stabilization step (see Figure 5 below) in which the load factor is instead kept constant and $\mathrm{J}$ is calculated for appropriately chosen successive designs.

\section{PROPOSED SPLITTING METHOD}

The latest release of VICONOPT incorporates VMULTI. This option in the code allows any number, $\mathrm{p}$, of stiffened panels (or other prismatic plate assemblies) to be designed simultaneously as physically separate parts of an aerospace structure, but with some design variables shared between them or linked to one another by linking equations. This option is necessary because if the panels were designed separately, the resulting lack of continuity of the design variables (e.g. skin thicknesses) where the panels meet would often lead to serious manufacturing difficulties. For example, physically adjacent panels may be constrained to have the same or related stiffener heights and pitch, or particular plies may be common to all panels, etc., e.g. so that plate thicknesses and or stiffener heights are uniform or vary linearly along the entire length of a wing surface. 
Let $\mathbf{K}_{\mathrm{m}, \mathrm{i}}, \mathbf{e}_{\mathrm{m}, \mathrm{i}}$ and $\mathbf{R}_{\mathrm{i}}$ be the $\mathbf{K}_{\mathrm{m}}, \mathbf{e}_{\mathrm{m}}$ and $\mathbf{R}$ for panel i (i=1,2,..,p). Then Figure 3 shows the Hermitian stiffness matrix for a two panel problem, i.e. $p=2$, using the VMULTI option. Clearly the number of eigenvalues, $\mathrm{J}_{\mathrm{p}}$, exceeded by an initial trial value is given by

$$
\mathrm{J}_{\mathrm{p}}=\sum_{\mathrm{i}=1}^{\mathrm{p}}\left(\sum_{\mathrm{m}}\left(\mathrm{J}_{0 \mathrm{~m}, \mathrm{i}}+\mathrm{s}\left\{\mathbf{K}_{\mathrm{m}, \mathrm{i}}\right\}\right)+\mathrm{s}\left\{\mathbf{R}_{\mathrm{i}}\right\}-\mathrm{r}_{\mathrm{i}}\right)
$$

This problem has much smaller orders for its $\mathbf{K}_{\mathrm{m}, \mathrm{i}}, \mathbf{e}_{\mathrm{m}, \mathrm{i}}$ and $\mathbf{R}_{\mathrm{i}}$ than those of the $\mathbf{K}_{\mathrm{m}}, \mathbf{e}_{\mathrm{m}}$ and $\mathbf{R}$ that would be obtained by applying the standard VICONOPT method to analyze the p panels as a single structure and therefore it gives a much faster solution.

The splitting method presented modifies the requirement of VMULTI that the panels should be entirely physically separate from each other to make it more powerful, as illustrated by the multi-spar wing box of Figure 1. The spars divide this wing box into cells of which three typical ones are shown, for which the spar wall stiffnesses are assumed to be split between adjacent cells in the ratio $\alpha:(1-\alpha)$ shown. Such splitting into cells has previously been investigated for analysis problems [17] but not for design. The present paper investigates the use of such splitting in design. This is relevant because although the standard VICON method enables the complete wing box to be designed as a whole structure, the computational time may be higher than is desirable for preliminary design, particularly if the wing box has a large number of cells. This time can be reduced significantly by using the VMULTI option to design the cells as separate panels, with the shared design variables chosen to include those properties of the shared spar walls that are not held constant during the design. 
The VICON method of VICONOPT is highly accurate, e.g.more accurate than F.E.M. with the size of elements likely to be used in practice, so long as the variables $\mathrm{q}$ and $\mathrm{r}$ of eqns (1) and (2) are high enough, i.e. so long as sufficient wavelengths are used and so long as the line support at $\mathrm{x}=0$ is represented by sufficient point supports. Therefore results given by applying the VICON method of VICONOPT to the complete structure are used in this paper as a datum against which the accuracy and computational efficiency of the proposed splitting method are assessed.

\section{THEORY FOR TIMING ESTIMATES RELATED TO COMPUTING J}

Time estimates can be made with confidence because it is known what tasks the computer is performing $[16,18]$. When computing $J$ or $J_{p}$ it is assumed that the times associated with the assembly of $\mathbf{K}_{\mathrm{m}}$ or $\mathbf{K}_{\mathrm{m}, \mathrm{i}}$ can be ignored, so that time estimates need to account only for the calculation of the plate stiffnesses and for the computation of the sign counts of the $\mathbf{K}_{\mathrm{m}}$ and $\mathbf{R}$ of eqn (2) or of the $\mathbf{K}_{\mathrm{m}, \mathrm{i}}$ and $\mathbf{R}_{\mathrm{i}}$ $(i=1,2, \ldots, p)$ of eqn $(3)$.

The mathematical manipulation is very similar for both of the $\mathrm{J}$ and $\mathrm{J}_{\mathrm{p}}$ cases, the only significant difference being the size of the problem and hence the time requirements. The time estimates follow from the work requirements and are taken from those given for $\mathbf{J}$ in ref. [18]. The stiffness matrices $\mathbf{K}_{\mathrm{m}}$ and $\mathbf{K}_{\mathrm{m}, \mathrm{i}}$ shown as shaded squares $(m=1,2,3,4)$ on Figures 2 and 3 are only coupled by, respectively, the $\mathbf{R}$ which replaces the null matrix of Figure 2 and by the corresponding uncoupled matrices $\mathbf{R}_{1}$ and $\mathbf{R}_{2}$ of Figure 3. Because of the lack of coupling, except via $\mathbf{R}$ or $\mathbf{R}_{\mathrm{i}}$ $(\mathrm{i}=1,2)$, each $\mathbf{K}_{\mathrm{m}}$ or $\mathbf{K}_{\mathrm{m}, \mathrm{i}}$ and its associated $\mathbf{e}_{\mathrm{m}}$ or $\mathbf{e}_{\mathrm{m}, \mathrm{i}}$ for any chosen $\lambda_{\mathrm{m}}$ on Figures 2 
and 3 can be operated on separately from other values of $\lambda_{m}$, which is equivalent to operating on

$$
A=\left[\begin{array}{cc}
K_{m} & e_{m} \\
e_{m}{ }^{H} & 0
\end{array}\right]\left(\operatorname{or} A=\left[\begin{array}{cc}
K_{m, i} & e_{m, i} \\
e_{m, i}^{H} & 0
\end{array}\right]\right)
$$

where $\mathrm{H}$ denotes Hermitian transpose.

The form of Gauss elimination described previously is applied to $\mathrm{A}$ ( or $\mathrm{A}_{\mathrm{i}}$ ) but is arrested after all rows within $\mathbf{K}_{\mathrm{m}}$ (or $\mathbf{K}_{\mathrm{m}, \mathrm{i}}$ ) have been pivotal. This standard procedure replaces $\mathbf{K}_{\mathrm{m}}$ (or $\mathbf{K}_{\mathrm{m}, \mathrm{i}}$ ) by the upper triangular form from which s $\left\{\mathbf{K}_{\mathrm{m}}\right\}$ (or $\mathrm{s}\left\{\mathbf{K}_{\mathrm{m}, \mathrm{i}}\right\}$ ) is derived and contributes to the generation of $\mathbf{R}$ (or $\mathbf{R}_{\mathrm{i}}(\mathrm{i}=1,2)$ ). Since $\mathbf{K}_{\mathrm{m}}$ (or $\mathbf{K}_{\mathrm{m}, \mathrm{i}}$ ) and the $\mathbf{R}$ (or $\mathbf{R}_{\mathrm{i}}$ ) matrices are Hermitian, or real and symmetric in some cases, Gauss elimination only involves operations on or above their diagonals. Note that two array locations are allocated for complex numbers and that each node has only four displacement amplitudes, because the longitudinally sinusoidal variation with half-wavelength $\lambda$ results in these four amplitudes defining the displacements in all six spatial degrees of freedom [14]. Hence Figures 4(a) - (d) show, for $p=3$, that when a typical row is pivotal, only elements in the shaded regions are operated on. Here $\mathrm{N}$ denotes the number of nodes and $\mathrm{B}$ is the bandwidth expressed as one plus the maximum node number difference for any pair of connected nodes.

The VICONOPT User Manual[19] gives the detailed formulas needed to calculate the time needed per iteration using the VICON method, which is defined as $\mathrm{T}_{\mathrm{v}}$ in this paper. These formulas are very sophisticated and allow for substructures, 
which are used to represent flanges in this paper, and also allow for beam substructures, supporting structures and repetitive analysis, although none of these are used in the example or equations given in this paper. Its value is calculated and printed by VICONOPT. $\mathrm{T}_{\mathrm{v}}$ contains machine dependent constants which must be found by using measured computer times for typical problems. Iteration times for the VMULTI option need to be found for each of the panels or cells $i(i=1,2, \ldots, p)$ and hence use exactly the same formulas. For the purpose of estimating $T_{v}$, Figure 4(b) replaces Figure 4(a) and Figure 4(d) replaces Figure 4(c). Hence simplified forms of the formulas used by VICONOPT for the wing box example of Section 6 follow from Figure 4 and are as follows.

Timing estimation formulas in simplified form needed by Section 6

For $\xi=0$ or 1

$$
\begin{aligned}
\mathrm{T}_{\mathrm{v}}=\mathrm{q}\{ & \left\{\alpha_{\mathrm{c}}\left\{32 \mathrm{~B}^{2}\left(\mathrm{~N}-\frac{2}{3} \mathrm{~B}\right)+8(\mathrm{~N}-\mathrm{B}) \mathrm{Br}+\frac{2}{3} \mathrm{Nr}^{2}+\left[\sum_{\mathrm{s}} 32 \mathrm{~B}_{\mathrm{s}}^{2}\left(\mathrm{~N}_{\mathrm{s}}-\frac{2}{3} \mathrm{~B}\right)\right]\right\}+\beta_{\mathrm{c}} \mathrm{P}\right\} \\
& +\alpha_{\mathrm{r}} \frac{1}{6} \mathrm{r}^{3}
\end{aligned}
$$

and for $0<\xi<1$

$$
\begin{aligned}
\mathrm{T}_{\mathrm{v}}=(2 \mathrm{q}+1) & \left\{\alpha_{\mathrm{c}}\left\{32 \mathrm{~B}^{2}\left(\mathrm{~N}-\frac{2}{3} \mathrm{~B}\right)+8(\mathrm{~N}-\mathrm{B}) \mathrm{Br}+\frac{2}{3} \mathrm{Nr}^{2}+\left[\sum_{\mathrm{s}} 32 \mathrm{~B}_{\mathrm{s}}^{2}\left(\mathrm{~N}_{\mathrm{s}}-\frac{2}{3} \mathrm{~B}\right)\right]\right\}+\beta_{\mathrm{c}} \mathrm{P}\right\} \\
& +\alpha_{\mathrm{c}} \frac{1}{6} \mathrm{r}^{3}
\end{aligned}
$$

where $\alpha_{c}$ is the time per update operation in complex Gauss elimination $\left(\alpha_{\mathrm{r}}\right.$ for real), $\beta_{\mathrm{c}}$ is the time required to calculate complex plate stiffness matrices of a plate, $\mathrm{P}$ is the number of plates in the assembly, $\sum_{\mathrm{s}}$ is a summation over all complex substructures, $\mathrm{N}_{\mathrm{s}}$ is the number of nodes in the substructure and $\mathrm{B}_{\mathrm{s}}$ equals three for doubly connected substructures and two for singly connected substructures. In eqns (5) and 
(6) the $32 \mathrm{~B}^{2}\left(\mathrm{~N}-\frac{2}{3} \mathrm{~B}\right)$ term is the usual expression for Gauss elimination within $\mathbf{K}_{\mathrm{m}}$, the $8(\mathrm{~N}-\mathrm{B}) \mathrm{Br}$ and $\frac{2}{3} \mathrm{Nr}^{2}$ terms are the corresponding work within $\mathbf{e}_{\mathrm{m}}$ and $\mathbf{R}$, respectively, and the $\frac{1}{6} \mathrm{r}^{3}$ term is for the final reduction of $\mathbf{R}$ to obtain $\mathrm{s}\{\mathbf{R}\}$.

\section{TIMING ESTIMATES FOR THE COMPLETE DESIGN PROCEDURE}

Figure 5 is a flow diagram for the design process of VICONOPT. The sizing strategy consists of a series of numbered steps which are now described.

The initial and final analyses of steps 1 and 7 perform buckling analyses as described earlier, beneath eqn (2). The initial stabilization of step 2 and the stabilization of step 6 factor the design variable ply thicknesses to just satisfy the most critical design requirements, which may be buckling or material strength constraints. This is achieved by an iterative approach similar to that of the initial design, the difference being that the eigenparameter that is changed between iterations is no longer the load factor but is instead the factor by which the ply thicknesses are multiplied. The constraint and sensitivity analysis of step 3 calculates a set of critical constraints and their sensitivities. This involves first calculating the unperturbed eigenvalue to high accuracy and then re-calculating it for small perturbations of each design variable in turn. The move limit calculations of step 4 calculate the move limits for the design variables [13]. The CONMIN [20] optimization of step 5 uses linear programming techniques to alter the design variables so that the plate assembly mass is reduced without violating the buckling, material and configurational constraints. Because the problem is very non-linear, step 6 adjusts the design to make 
it just stable and the CONMIN loop uses rationally chosen [13] revised move limits at step 4 and continues until appropriate convergence criteria are met. The sizing cycle then calculates new constraints and sensitivities at step 3, ultimately leading to an adequately converged design which is analyzed to high accuracy at step 7 .

VICONOPT is a sophisticated program with many refinements [21-24] including linking it to a space frame program, the details of which are spread over many papers. The basis of the timing estimates for each of the steps are given in Section 6 and use principally $\mathrm{T}_{\mathrm{v}}$, calculated by eqns (5) and (6). No timings are included for VIPASA type calculations because although these are performed to guard against short wavelength buckling they only take a small time in comparison to the total, which is dominated by VICON type calculations.

\section{TEST STRUCTURE AND RESULTS}

\section{Details of the example}

The wing box test specimen considered for computer modelling had three cells, as shown in Figure 6. It is a variation on the dimensions of a wing box which was obtained from British Aerospace Defence (Military Aircraft) for an earlier [17] demonstration of a structure splitting method for analysis, as opposed to the present design application.

Tables 2 and 3 show the lay-ups and loading of the structure. $\mathrm{N}_{\mathrm{S}}$ is an inplane shear load per unit width (positive to the right on Figure 6) and ply angles are measured clockwise from the longitudinal axis. All lay-ups are symmetric and the flanges are identical to the webs on Figure 6 . The unusual angles are due to a $\left(0^{\circ}, 90^{\circ}\right.$, 
$45^{\circ},-45^{\circ}$ ) lay-up being rotated by $6^{\circ}$. All the plies have the same elastic properties with $\mathrm{E}_{1}=130 \mathrm{kN} / \mathrm{mm}^{2} ; \mathrm{E}_{2}=9 \mathrm{kN} / \mathrm{mm}^{2} ; \mathrm{G}_{12}=4.8 \mathrm{kN} / \mathrm{mm}^{2} ; v_{12}=0.3$ and density 1.598 $\mathrm{kg} / \mathrm{m}^{3}$.

Each flange is connected to the skin by a single line of bolts (see Figure 6) which are the only connection between the spars and the skins. The wing box was split into cells along the bolt lines, with the spar stiffnesses divided equally between adjacent cells, i.e. $\alpha=0.5$ on Figure 1 . This value of $\sigma=0.5$ was applied to the loads and stiffnesses in the hatched portions of the spars, but not to their thicknesses, which retained their values for the original box. A lower bound answer is guaranteed for analysis $[17,25]$, which implies that an upper bound must be obtained when designing by this splitting method. Hence the design which results must overestimate the optimum design mass and must have a reserve of strength, i.e. the design is conservative.

The design was defined such that the external dimensions were unchanged i.e. the aerodynamic properties were not allowed to change, whereas the skin thicknesses and the point support spacing were allowed to change. Lay-ups were balanced through linking. Figure 7 shows how the problem was modelled for VICONOPT. The point supports are shown as crosses. They are located such that each bolt position corresponds to a point support at which it can be seen that the skin and/or the flanges must be connected with an offset which was modelled using a standard feature of VICONOPT $[14,19]$. Vertical displacements $(\mathrm{z})$ and rotations about the $\mathrm{x}$ axis $(囚)$ were constrained at all point supports on the top and bottom skins and displacement in the y direction (v) was constrained at the spar mid-point nodes. 


\section{Design results}

There were twelve design variables. Six of these were ply thicknesses as follows. Table 2 gives the initial thicknesses of all components. The four spars shown in Figure 6 were of initial equal thickness $1.92 \mathrm{~mm}$. For the two internal spars the plies of the web and flanges were assumed all to be of equal thickness $t_{1}$ throughout the design process and this thickness was one of the six thickness design variables. Similarly all plies of the two outer spars were equal and this thickness $t_{2}$ was the second design variable. For the skin component of initial thickness $5.28 \mathrm{~mm}$ the $-84^{\circ}$ and $6^{\circ}$ plies were initially of equal thickness and shared the same thickness $t_{3}$ throughout design, giving the third design variable. Similarly, the equal thicknesses of the $51^{\circ}$ and $-39^{\circ}$ plies formed the fourth independent variable $t_{4}$. For the skin component of initial thickness $5.78 \mathrm{~mm}$ the $-84^{\circ}$ and $6^{\circ}$ plies were initially of equal thickness and shared the same thickness $t_{5}$ throughout design, giving the fifth design variable, while the equal thicknesses of the $51^{\circ}$ and $-39^{\circ}$ plies formed the sixth independent variable $t_{6}$. The remaining six independent variables were the breadths shown thick on Figure 7. The remaining breadths were linked to keep the total width of the panel at $725 \mathrm{~mm}$ and its height at $110 \mathrm{~mm}$, as shown in Figure 7.

Table 4 shows the principal results for the VICONOPT and VMULTI designs, while Table 5 shows the initial, lower bound and final values for the ply thicknesses and for the independent and dependent width variables shown in Figure 7.

Bandwidth and constraints. 
Table 6 shows that the VMULTI option has the advantage that the minimum obtainable bandwidth is lower than for the VICON method. Here the 9 and 18 cell structures were modelled by repeating cell 2 seven times for the 9 cell structure and sixteen times for the 18 cell structure. Figures 2-4 show that for the VMULTI option the work done on the constraint matrices is lower than for the corresponding VICON method. For example Table 6 shows that for all of the 3, 9 and 18 cell structures the bandwidths $B_{i}$ are equal to three or four for the VMULTI option, whereas $B=5$ for the VICON method.

\section{Iteration times}

The timing estimates and actual measured computer run times contained in this paper are for a VAX - 4500 computer. Table 7 shows the predicted time needed per iteration for the VICON method, $\mathrm{T}_{\mathrm{v}}$, and for cell $\mathrm{i}$ when using the VMULTI option, $\mathrm{T}_{\mathrm{i}}(\mathrm{i}=1,2,3)$. It also shows the corresponding measured times per iteration, $\mathrm{T}_{\mathrm{vA}}$ and $\mathrm{T}_{\mathrm{iA}}$, and the total times used in the complete analysis of step 1, which are equal to $\sum \mathrm{T}_{\mathrm{vA}}$ and $\sum \sum_{\mathrm{i}=1}^{\mathrm{p}} \mathrm{T}_{\mathrm{iA}}$, where $\mathrm{p}=3,9$ or 18 for these examples and the summations without limits are over all the iterations needed to obtain a complete analysis.

Table 8 shows the actual times for each of the design steps in Figure 5 for the three cell structure, with the exception of step 4 , which takes very little time. The information in the last two columns of Table 7 was used to estimate the time requirements for the complete 9 and 18 cell designs as follows. It was assumed that the times for all the steps increase by the same factor when the number of cells is 
changed. For example the final column of Table 7 gives the factor as $270 / 45=6$ for VMULTI design of the 18 and 3 cell structures. Hence the values in the final (i.e. seventh) column of Table 8 were obtained by multiplying the values in the third column by six. This is a reasonable procedure because all of steps 1-7 except for the relatively quick steps 4 and 5 are dominated by $\mathrm{T}_{\mathrm{vA}}$ for VICON designs and by $\mathrm{T}_{\mathrm{iA}}$ for VMULTI designs. However the results are only meant to be of first order accuracy, e.g. because they inevitably assume that all the designs will perform the same number of CONMIN cycles and the same number of sizing cycles.

\section{CONCLUSIONS}

The process of splitting structures into cells has been demonstrated to be more efficient than designing the complete structure. The structure designed by the splitting method will have a critical buckling load that exceeds or equals the buckling load obtained by designing the complete structure without splitting, i.e. the design is guaranteed to be safe but somewhat overweight. For realistic sized problems in the design of wing boxes, where there may be between 9 and 18 cells, preliminary design will be achieved much more quickly by using the splitting method presented.

\section{Acknowledgments}

The first author gratefully acknowledges financial support from the Engineering and Physical Sciences Research Council and British Aerospace Airbus Division (Filton). 


\section{REFERENCES}

1. Viswanathan, A. V., Tamekuni, M. and Tripp, L. L., Elastic stability of biaxially loaded longitudinally stiffened composite structures. AIAA Journal, 1973, 11, 1553-1559.

2. Dawe, D. J. and Peshkam, V., Buckling and vibration of long plate structures by complex finite strip methods. International Journal of Mechanical Sciences, 1990, 32, 743-766.

3. Wittrick, W. H. and Horsington, R. W., Buckling and vibration of composite folded-plate structures of finite length in combined shear and compression. Proceedings of the Royal Society series A, 1984, 392, 107-144.

4. Godoy, L. A., Finite strip methods for instability of prismatic plate assemblies. Engineering Analysis, 1988, 5, 100-107.

5. Plank, R. J. and Wittrick, W. H., Buckling under combined loading of thin, flatwalled structures by a complex finite strip method, International Journal for Numerical Methods in Engineering, 1974, 8, 323-339.

6. Garstecki, A., and Kakol, W., Structural sensitivity analysis in eigenvalue problems using finite strip method. American Society of Mechanical Engineers, Design Engineering Division, 1994, 69, 393-398. 
7. Dawe, D. J. and Craig, T. J., Buckling and vibration of shear deformable prismatic plate structures by a complex finite strip method. International Journal of Mechanical Sciences, 1988, 30, 77-99.

8. Graves Smith, T. R., The finite strip analysis of thin-walled structures Developments in Thin-Walled Structures 3, Elsevier, London, 1987, pp 205-235.

9. Hinton, E., Ozakca, M. and Rao, N. V. R., Structural shape optimization of vibrating shells and folded plates using two-noded finite strips. Engineering Computations, 1993, 10, 139-157.

10.Hinton, E. and Rao, N. V. R., Structural shape optimization of shells and folded plates using two-noded finite strips. Computers and Structures, 1993, 46, 1055 1071.

11.Bushnell, D. and Bushnell, W. D., Minimum-weight design of a stiffened panel via PANDA2 and evaluation of the optimized panel via STAGS. Computers and Structures, 1994, 50, 569-602.

12.Hinton, E., Petrinic, N. and Ozakca, M., Buckling analysis and shape optimization of variable thickness prismatic folded plates. Engineering Computations, 1993, 10, 493-498. 
13.Butler, R. and Williams, F. W., Optimum design using VICONOPT, a buckling and strength constraint program for prismatic assemblies of anisotropic plates. Computers and Structures, 1992, 43, 699-708.

14.Wittrick, W. H. and Williams, F. W., Buckling and vibration of anisotropic or isotropic plate assemblies under combined loadings. International Journal of Mechanical Sciences, 1974, 16, 209-239.

15.Anderson, M. S., Williams, F. W. and Wright, C. J., Buckling and vibration of any prismatic assembly of shear and compression loaded anisotropic plates with an arbitrary supporting structure. International Journal of Mechanical Sciences, 1983, 25, 585-596.

16.Williams, F. W. and Anderson, M. S., Buckling and vibration analysis of skewloaded prismatic plate assemblies with supporting structures, utilizing symmetric or repetitive cross-sections. Aspects of the Analysis of Plate Structures- A Volume in Honour of W. H. Wittrick, Oxford University Press, Oxford, 1985, pp. 51-71.

17.Aston, G. and Williams, F.W., Simplified methods for the buckling analysis of composite multi-spar wing boxes. Composite Structures, 1994, 28, 215-223. 
18.Kennedy, D., Williams, F.W. and Anderson, M.S., Buckling and vibration analysis of laminated panels using VICONOPT. Journal of Aerospace Engineering ASCE, 1994, 7, 245-262.

19.Williams, F. W., Kennedy, D., Anderson, M. S. and Edwards, D.A., User Manual for VICONOPT Release 1.3, January 1996, University of Wales Cardiff, P.O. Box 686, Cardiff, CF2 3TB, pp 1-210.

20.Vanderplaats, G.N. and Moses, F., Structural optimization by methods of feasible directions. Computers and Structures, 1973, 3, 739-755.

21.Kennedy, D. and Williams, F.W., More efficient use of determinants to solve transcendental structural eigenvalue problems reliably. Computers and Structures, 1991, 41, 973-979.

22.Anderson, M.S. and Williams, F.W., BUNVIS-RG: Exact frame buckling and vibration program, with repetitive geometry and substructuring. Journal of Spacecraft and Rockets, 1987, 24, 353-361.

23.Williams P.W.L., Williams, F.W. and Kennedy, D., Inclusion of transverse shear deformation in optimum design of aircraft wing panels. AIAA Journal, 1996, 34, $2456-2458$ 
24.Powell S.M., Kennedy D. and Williams F.W., Efficient multi-level substructuring with constraints for buckling and vibration analysis of prismatic plate assemblies. International Journal of Mechanical Sciences, 1997, 39, 795-805.

25.Williams, F. W. and Aston, G., Assessment of simple procedures for obtaining lower bound buckling loads, 11th Australasian Conference on the Mechanics of Structures and Materials, University of Auckland, Auckland, New Zealand, 1988, pp343-349. 
Figure Captions:

Figure 1. A multi spar wing box: (a) typical cross section; (b) split into cells and; (c) spar split at the bolt lines.

Figure 2. Matrix used by standard VICON method of VICONOPT. The shaded areas contain only the non-zero elements, the squares labeled $\mathbf{K}_{\mathrm{m}}(\mathrm{m}=1,2,3,4)$ are the stiffness matrices for each of the four values of $\lambda_{\mathrm{m}}$, the triangular matrices, $\mathrm{e}_{\mathrm{m}}$, represent matrices which are only approximately triangular [16] and contain the constraints which couple the different values of $\lambda_{\mathrm{m}}$.

Figure 3. Matrix for a two structure VMULTI type problem. The shaded areas contain the only non-zero elements, the squares labeled $\mathbf{K}_{\mathrm{m}, 1}$ and $\mathbf{K}_{\mathrm{m}, 2}(\mathrm{~m}=1,2,3,4)$ are the stiffness matrices for each of the four values of $\lambda_{\mathrm{m}}$, the triangular matrices, $\mathbf{e}_{\mathrm{m}, 1}$, and $\mathbf{e}_{\mathrm{m}, 2}$ represent matrices which are only approximately triangular [16] and contain the constraints which couple the different values of $\lambda$. The shaded squares denoted $\mathbf{R}_{1}$ and $\mathbf{R}_{2}$ are initially null but become $\mathbf{R}_{1}$ and $R_{2}$ after Gauss elimination of all rows within the $\mathbf{K}_{\mathrm{m}, \mathrm{i}}(\mathrm{m}=1,2,3,4 ; \mathrm{i}=1,2)$.

Figure 4. Form of matrices $\mathrm{A}$ and $\mathrm{A}_{\mathrm{i}}$. (a) True form of A (VICON) showing only one wavelength to save space; (b) form used to estimate $T_{v}$; (c) true form of $A_{i}$ (VMULTI) again showing only one wavelength per structure to save space;(d) form used to estimate $T_{i}(i=1,2,3)$.

Figure 5. VICONOPT design flow chart. 
Figure 6. Test specimen representing wing box of Figure 1(a). The length is $280 \mathrm{~mm}$ and all the other dimensions are for the initial design and are also in $\mathrm{mm}$.

Figure 7. Modelling of wing box using: (a) VICONOPT; (b) VMULTI. Nodes in the upper skin are vertically above their counterparts in the lower skin, so the design variables apply to both skins. Breadths $b_{1}-b_{6}$ were the independent design variables and are shown thick. Corresponding breadths were design variables in the VMULTI option. Other breadths which were equal to the independent design variables are also labelled $b_{1}-b_{6}$ and the dependent breadths are denoted $x_{1}-x_{4}$. The dependency of $x_{1}-x_{4}$ on $b_{1}, b_{3}$ and $b_{6}$ was not sufficiently relevant to be defined in this paper. 
Table 1 . Half wavelengths $\lambda$ used in VICON type analysis of a plate assembly of length $l$ with $\mathrm{q}=2$ ( $\infty$ denotes a rigid body translation).

\begin{tabular}{cl}
\hline \hline$\xi$ & \multicolumn{1}{c}{$\lambda$} \\
\hline 0 & $\infty, l / 2$ \\
0.25 & $4 l,-4 l / 7,4 l / 9,-4 l / 15,4 l / 17$ \\
0.5 & $2 l,-2 l / 3,2 l / 5,-2 l / 7,2 l / 9$ \\
0.75 & $4 l / 3,-4 l / 5,4 l / 11,-4 l / 13,4 l / 19$ \\
1 & $l, l / 3$ \\
\hline \hline
\end{tabular}


Table 2. Lay-up of plies used in wing box.

\begin{tabular}{|c|c|}
\hline $\begin{array}{l}\text { Components of } \\
\text { initial thicknesses }\end{array}$ & Ply angles in degrees \\
\hline 1.92 & $45-4545-4545-4545-4545-4545-45 \mathrm{~S}$ \\
\hline 5.28 & $-846-8465151-39-39-8465151-39-39-51-39-8465151-39-39-39-39 \mathrm{~S}$ \\
\hline 5.78 & $-846-8465151-39-39-8465151-39-39-51-39-8465151-39-3951-3951-39 \mathrm{~S}$ \\
\hline
\end{tabular}

Table 3. Loadings per unit width on the loaded components of the wing box. The webs and the flanges were unloaded.

\begin{tabular}{cc}
\hline \hline Initial skin thickness & $\mathrm{N}_{\mathrm{S}}$ \\
$(\mathrm{mm})$ & $(\mathrm{N} / \mathrm{mm})$ \\
\hline 5.78 & 1680 \\
5.28 & -1050 \\
\hline \hline
\end{tabular}


Table 4. Results for optimization of 3 cell structure. The number of CONMIN cycles is the total for all the design cycles.

\begin{tabular}{ccc}
\hline \hline & VICON & VMULTI \\
\hline Initial mass $(\mathrm{kg})$ & 4.146 & 4.146 \\
Initial stable mass $(\mathrm{kg})$ & 4.834 & 4.902 \\
Number of design cycles & 5 & 4 \\
Number of CONMIN cycles & 22 & 18 \\
Final mass (kg) & 4.571 & 4.590 \\
CPU time(sec) & 1898 & 1002 \\
\hline \hline
\end{tabular}


Table 5. Initial, lower bound and final values for independent and dependent variables $(\mathrm{mm})$.

\begin{tabular}{|c|c|c|c|c|}
\hline \multirow[b]{2}{*}{ Variable } & \multirow[b]{2}{*}{ Initial value } & \multirow{2}{*}{$\begin{array}{l}\text { Lower } \\
\text { bound }\end{array}$} & \multicolumn{2}{|c|}{ Final value } \\
\hline & & & VICON & VMULTI \\
\hline$\overline{t_{1}}$ & 0.08 & 0.08 & 0.117 & 0.130 \\
\hline$t_{2}$ & 0.08 & 0.08 & 0.0931 & 0.109 \\
\hline$t_{3}$ & 0.08 & 0.08 & 0.0800 & 0.0801 \\
\hline $\mathrm{t}_{4}$ & 0.125 & 0.08 & 0.134 & 0.133 \\
\hline$t_{5}$ & 0.08 & 0.08 & 0.0800 & 0.0801 \\
\hline $\mathrm{t}_{6}$ & 0.125 & 0.08 & 0.144 & 0.138 \\
\hline$b_{1}$ & 24 & 7 & 18.9 & 16.7 \\
\hline $\mathrm{b}_{2}$ & 18.5 & 16 & 16 & 16 \\
\hline $\mathrm{b}_{3}$ & 106 & - & 114.9 & 118.3 \\
\hline $\mathrm{b}_{4}$ & 8.5 & 7 & 7 & 7 \\
\hline $\mathrm{b}_{5}$ & 16.5 & 16 & 16 & 16 \\
\hline $\mathrm{b}_{6}$ & 124 & - & 122.7 & 117.7 \\
\hline $\mathrm{x}_{1}$ & 96 & - & 105.9 & 109.4 \\
\hline $\mathrm{x}_{2}$ & 116 & - & 113.7 & 108.7 \\
\hline $\mathrm{x}_{3}$ & 116.5 & - & 115.0 & 118.7 \\
\hline $\mathrm{x}_{4}$ & 118.5 & - & 115.0 & 118.7 \\
\hline
\end{tabular}


Table 6. $\mathrm{N}, \mathrm{r}$ and $\mathrm{B}$ for the structure used in the VICON design and $\mathrm{N}_{\mathrm{i}}, \mathrm{r}_{\mathrm{i}}$ and $\mathrm{B}_{\mathrm{i}}$ for each structure used by the VMULTI option.

\begin{tabular}{|c|c|c|c|c|c|c|c|}
\hline & \multicolumn{3}{|c|}{ VICON } & & \multicolumn{3}{|c|}{ VMULTI } \\
\hline & 3 cells & 9 cells & 18 cells & & Cell 1 & Cell 2 & Cell 3 \\
\hline $\mathrm{N}$ & 28 & 70 & 133 & $\mathrm{~N}_{\mathrm{i}}$ & 12 & 10 & 12 \\
\hline$r$ & 52 & 130 & 247 & $r_{i}$ & 22 & 18 & 22 \\
\hline B & 5 & 5 & 5 & $\mathrm{~B}_{\mathrm{i}}$ & 4 & 3 & 4 \\
\hline
\end{tabular}


Table 7. Estimated and actual times per iteration for $\xi=0$ and, in the last two columns, total times for the initial analysis of step 1 of Figure 5 (in CPU sec).

\begin{tabular}{ccccccccccc}
\hline \hline No. of cells & $\mathrm{T}_{\mathrm{v}}$ & $\mathrm{T}_{1}$ & $\mathrm{~T}_{2}$ & $\mathrm{~T}_{3}$ & $\mathrm{~T}_{\mathrm{vA}}$ & $\mathrm{T}_{1 \mathrm{~A}}$ & $\mathrm{~T}_{2 \mathrm{~A}}$ & $\mathrm{~T}_{3 \mathrm{~A}}$ & $\sum \mathrm{T}_{\mathrm{vA}}$ & $\sum \sum_{\mathrm{i}=1}^{\mathrm{p}} \mathrm{T}_{\mathrm{iA}}$ \\
& & & & & & & & & & \\
\hline 3 & 0.46 & 0.11 & 0.083 & 0.11 & 0.44 & 0.12 & 0.10 & 0.12 & 62 & 45 \\
9 & 4.1 & 0.11 & 0.083 & 0.11 & 4.3 & 0.12 & 0.10 & 0.12 & 740 & 120 \\
18 & 23.8 & 0.11 & 0.083 & 0.11 & 37 & 0.12 & 0.10 & 0.12 & 5200 & 270 \\
\hline \hline
\end{tabular}


Table 8. Actual and predicted times for the completed design (CPU seconds)

\begin{tabular}{ccccccc}
\hline \hline & \multicolumn{2}{c}{3 cells, actual } & \multicolumn{2}{c}{9 cells, predicted } & \multicolumn{2}{c}{18 cells, predicted } \\
Step No. & VICON & VMULTI & VICON & VMULTI & VICON & VMULTI \\
\hline 1 & 62 & 45 & 740 & 120 & 5200 & 270 \\
2 & 10 & 15 & 119 & 40 & 839 & 90 \\
3 & 951 & 616 & 11350 & 1643 & 79761 & 3696 \\
5 & 99 & 95 & 1182 & 253 & 8303 & 570 \\
6 & 709 & 178 & 8462 & 475 & 59465 & 1068 \\
7 & 66 & 52 & 788 & 139 & 5535 & 312 \\
Totals & 1897 & 1001 & 22641 & 2670 & 159103 & 6006 \\
\hline \hline
\end{tabular}


(a)

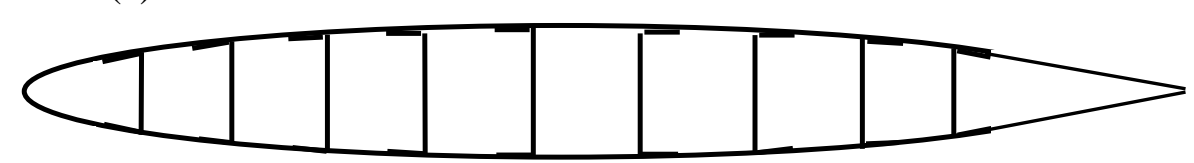

(b)

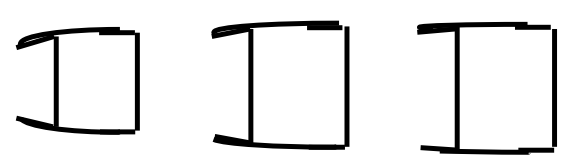

(c)

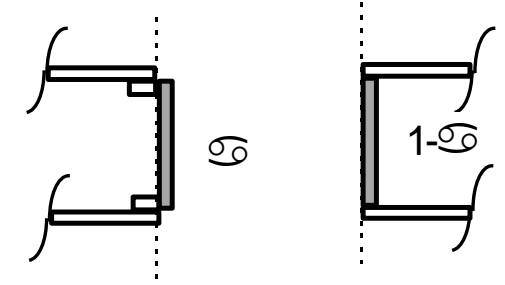

Figure 1. A multi-spar wing box: (a) typical cross section; (b) split into cells and; (c) spar split at the bolt lines. 


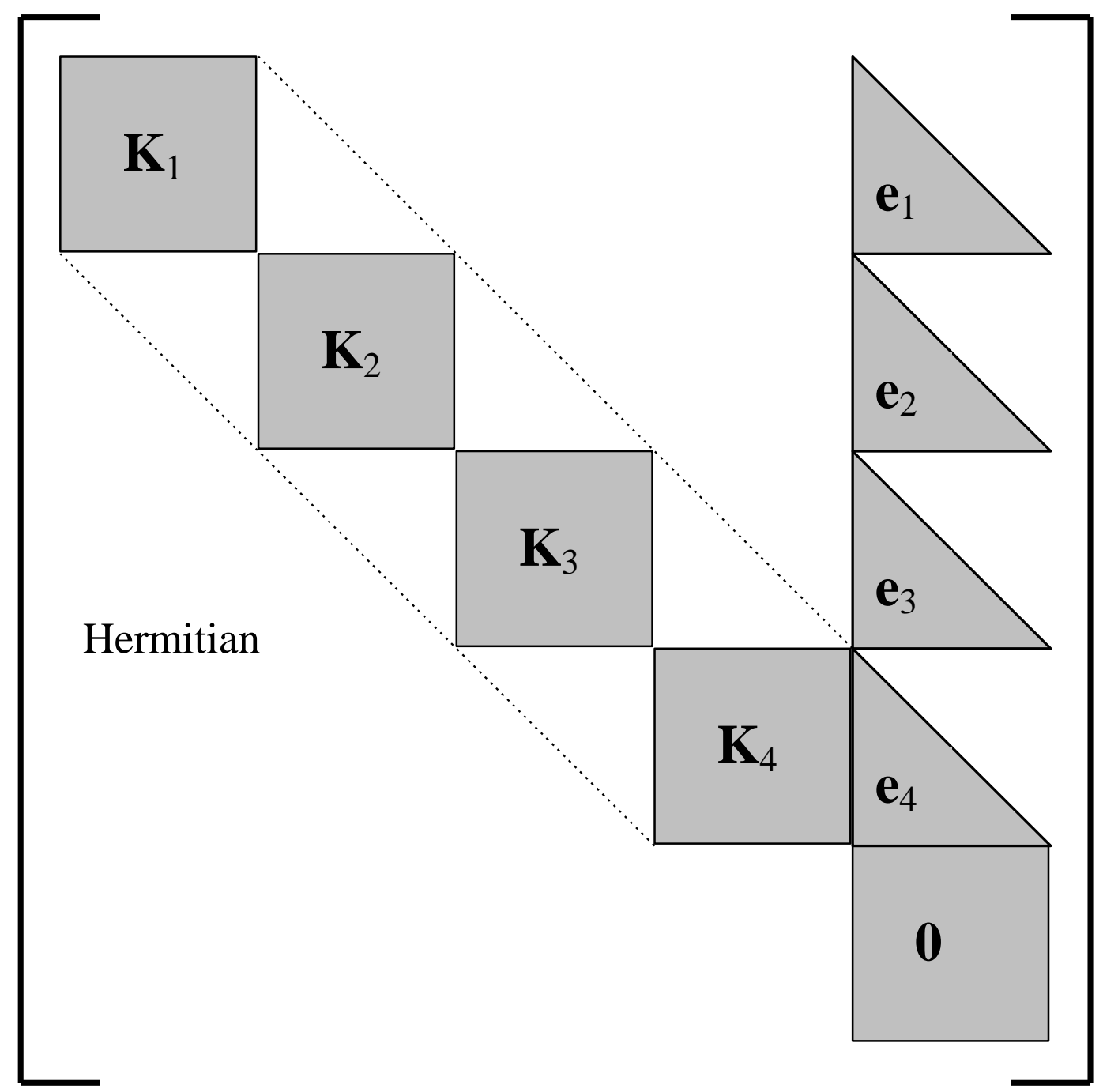

Figure 2. Matrix used by standard VICON method of VICONOPT. The shaded areas contain only the non-zero elements, the squares labeled $\mathbf{K}_{\mathrm{m}}(\mathrm{m}=1,2,3,4)$ are the stiffness matrices for each of the four values of $\lambda_{\mathrm{m}}$, the triangular matrices, $\mathbf{e}_{\mathrm{m}}$, represent matrices which are only approximately triangular [16] and contain the constraints which couple the different values of $\lambda_{\mathrm{m}}$. 


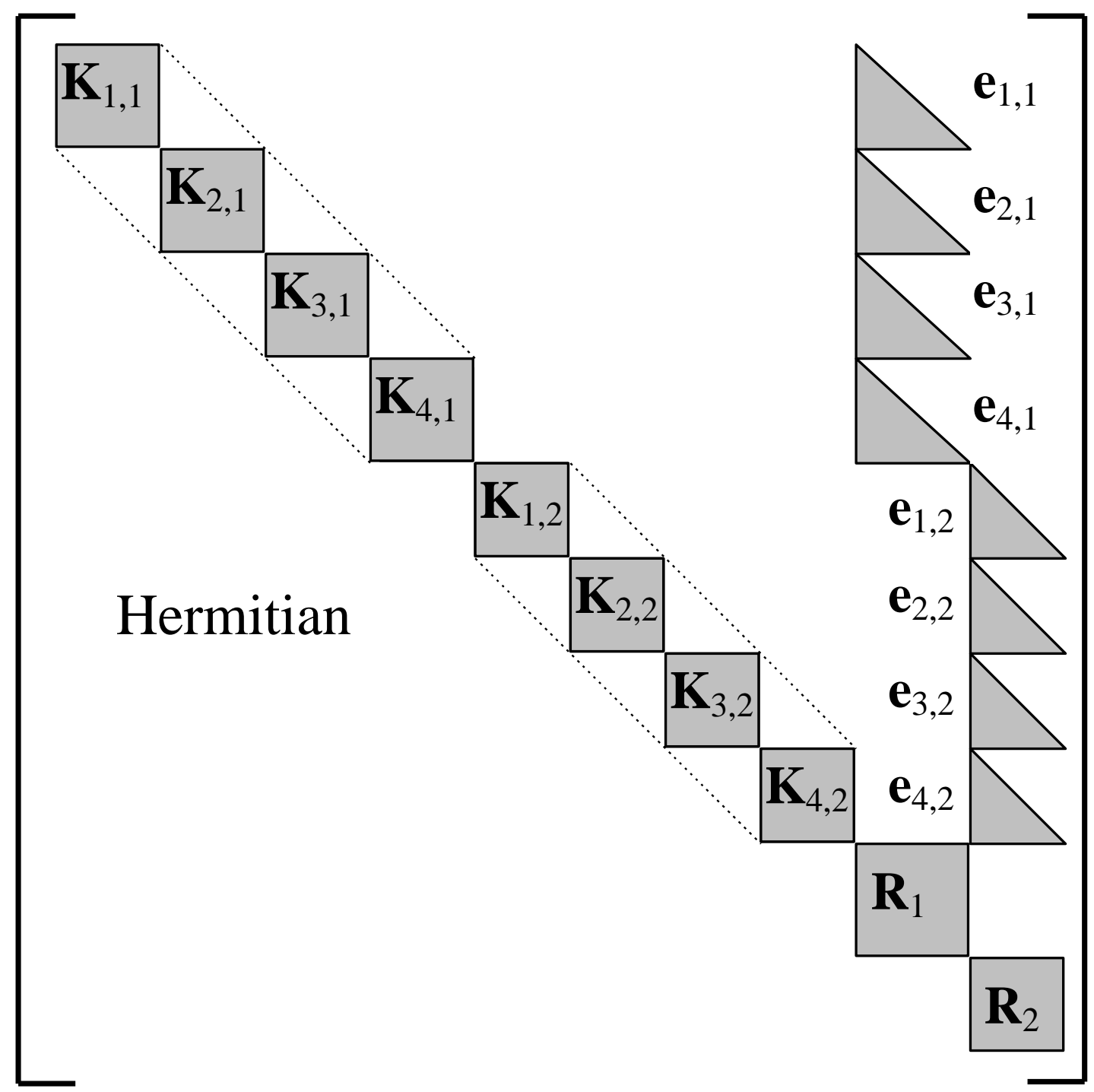

Figure 3. Matrix for a two structure VMULTI type problem. The shaded areas contain the only non-zero elements, the squares labeled $\mathbf{K}_{\mathrm{m}, 1}$ and $\mathbf{K}_{\mathrm{m}, 2}(\mathrm{~m}=1,2,3,4)$ are the stiffness matrices for each of the four values of $\lambda_{\mathrm{m}}$, the triangular matrices, $\mathbf{e}_{\mathrm{m}, 1}$, and $\mathbf{e}_{\mathrm{m}, 2}$ represent matrices which are only approximately triangular [16] and contain the constraints which couple the different values of $\lambda$. The shaded squares denoted $\mathbf{R}_{1}$ and $\mathbf{R}_{2}$ are initially null but become $\mathbf{R}_{1}$ and $\mathbf{R}_{2}$ after Gauss elimination of all rows within the $\mathbf{K}_{\mathrm{m}, \mathrm{i}}(\mathrm{m}=1,2,3,4 ; \mathrm{i}=1,2)$. 


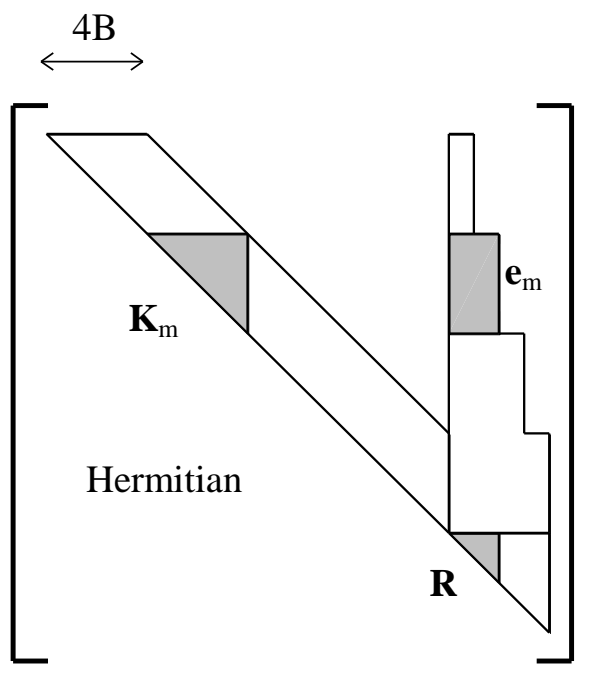

(a)

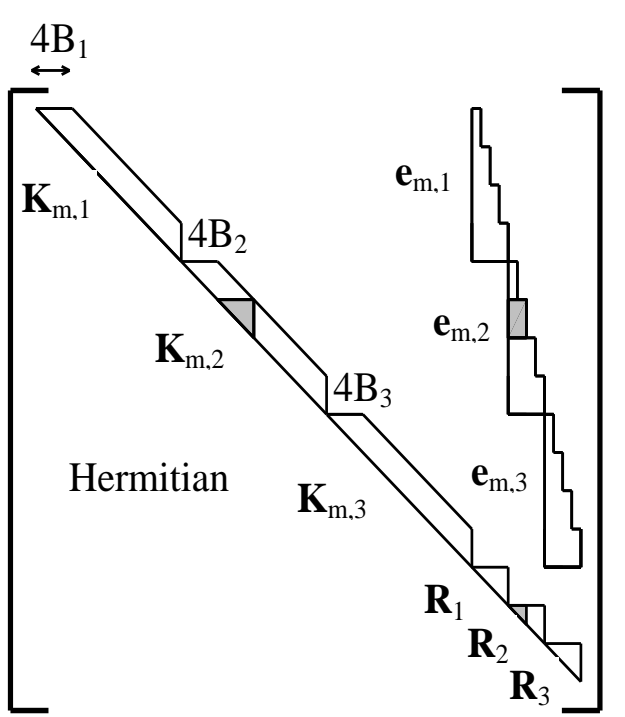

(c)

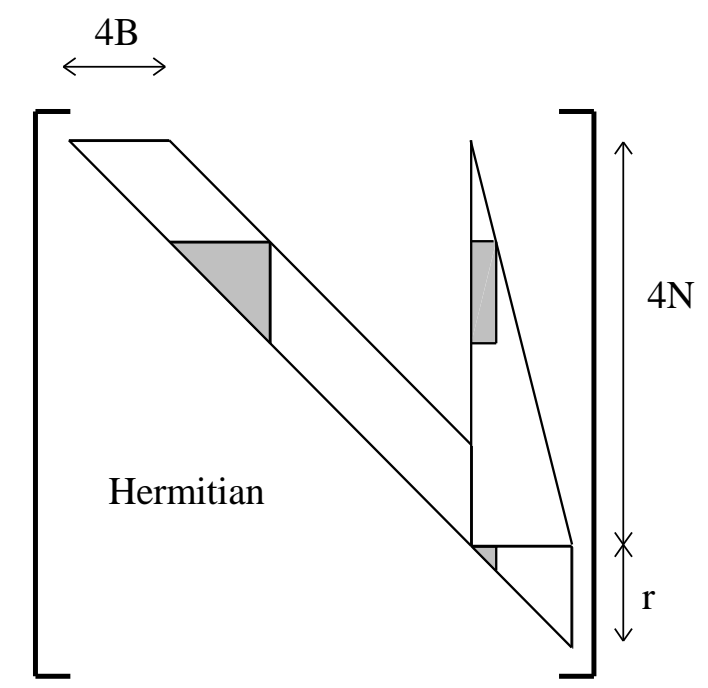

(b)

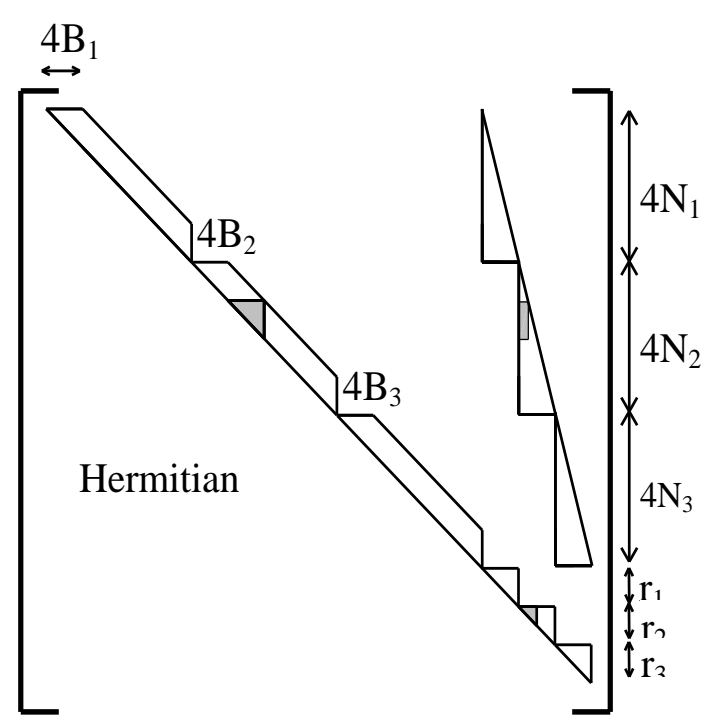

(d)

Figure 4. Form of matrices $\mathrm{A}$ and $\mathrm{A}_{\mathrm{i}}$. (a) True form of A (VICON) showing only one wavelength to save space; (b) form used to estimate $T_{v}$; (c) true form of $A_{i}$ (VMULTI) again showing only one wavelength per structure to save space;(d) form used to estimate $T_{i}(i=1,2,3)$. 


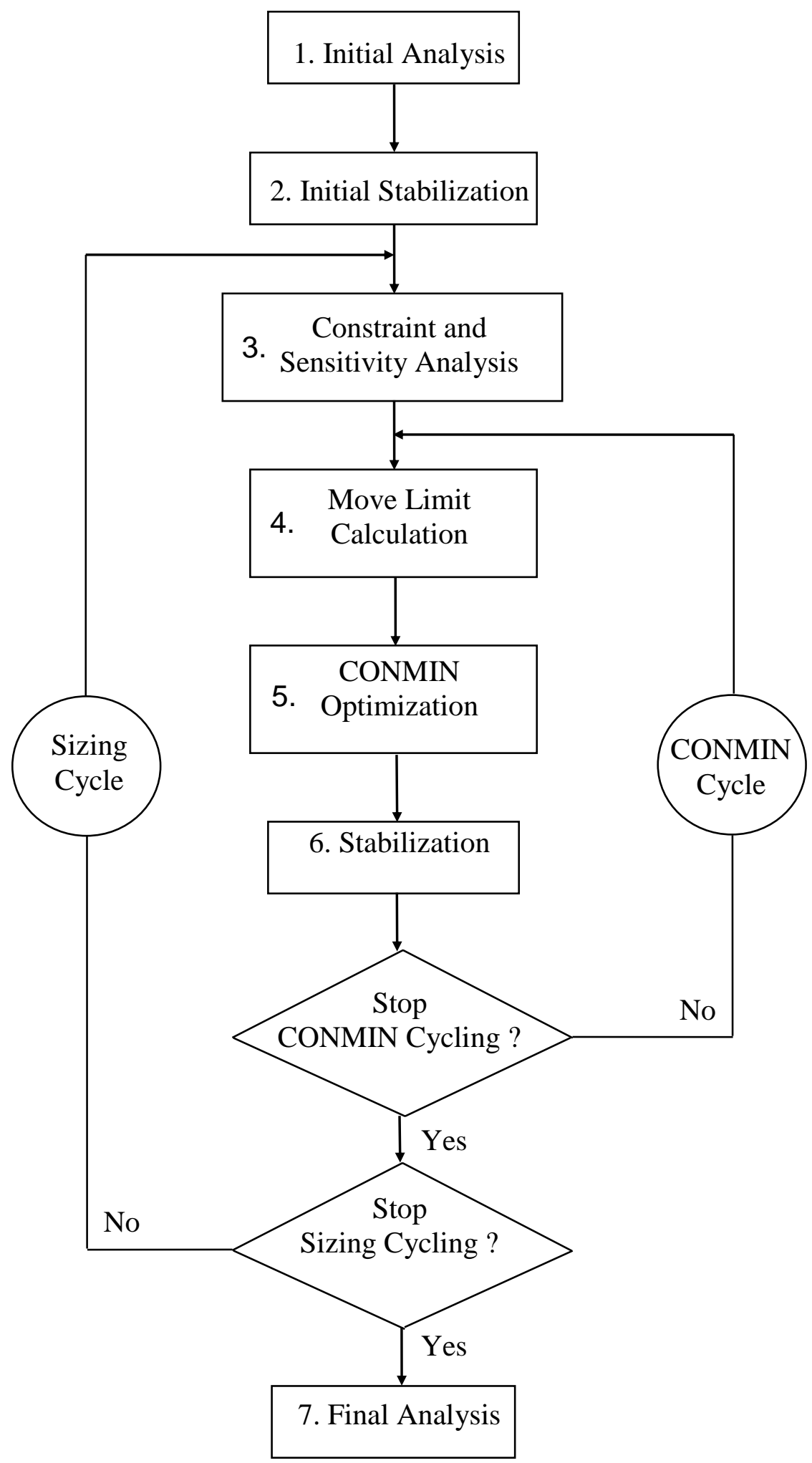

Figure 5. VICONOPT design flow chart 


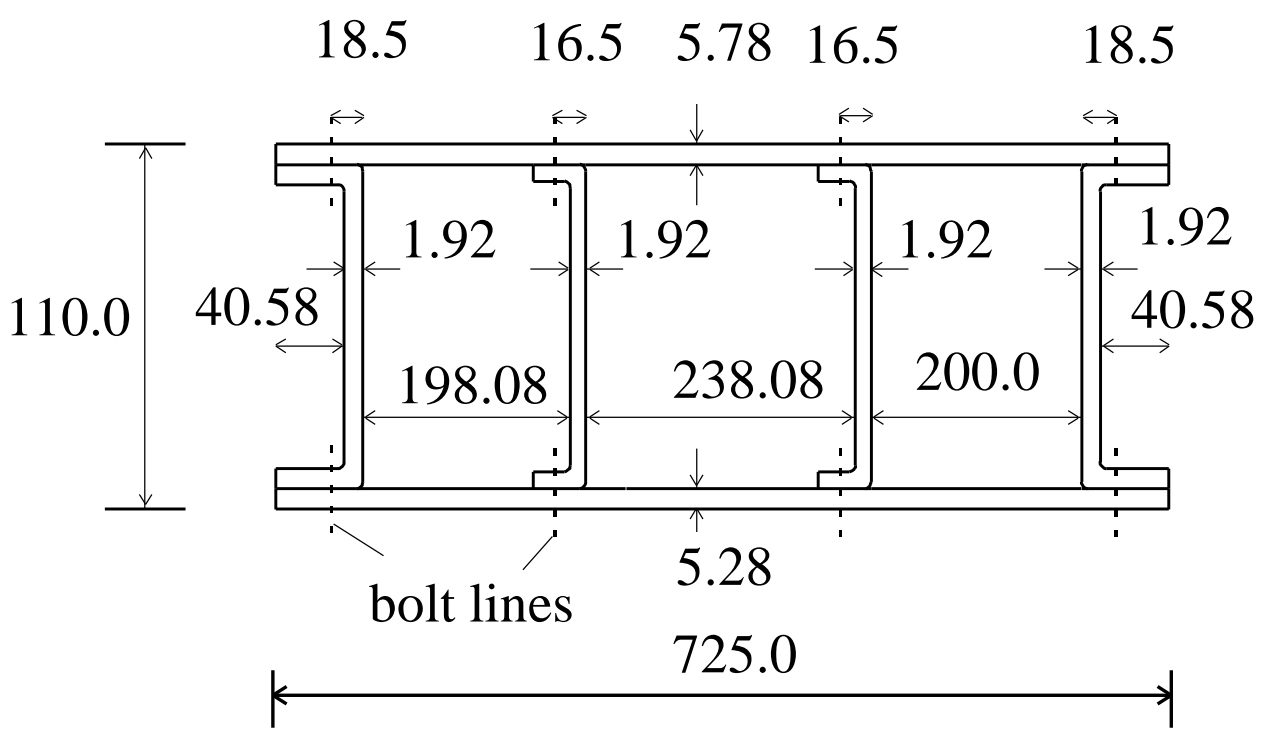

Figure 6. Test specimen representing wing box of Figure 1(a). The length is $280 \mathrm{~mm}$ and all the other dimensions are for the initial design and are also in $\mathrm{mm}$. 
(a)

$725 \mathrm{~mm}$

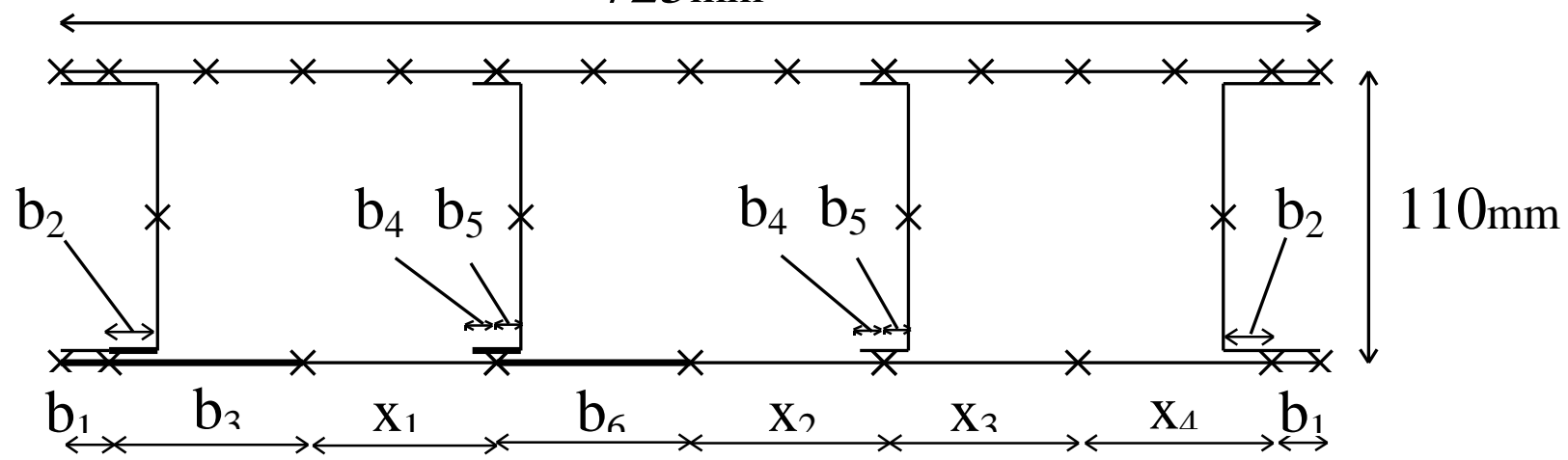

$\mathrm{X}, \mathrm{u}$

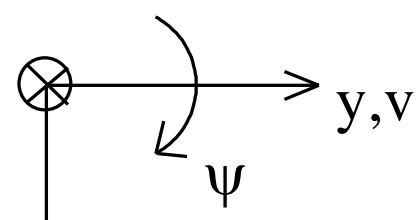

$\downarrow$

$\mathrm{Z}, \mathrm{W}$

(b)

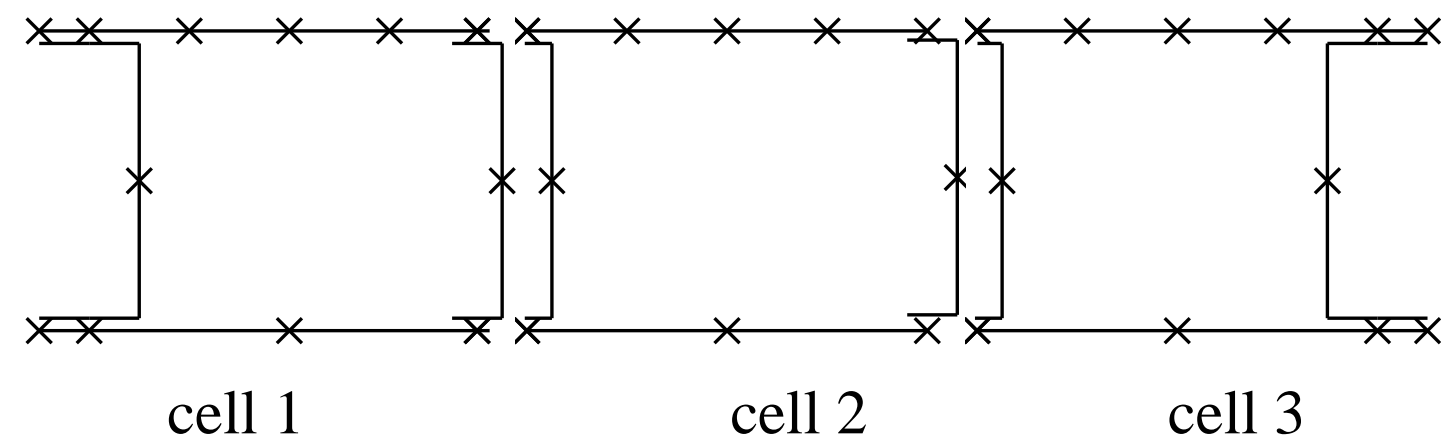

Figure 7. Modelling of wing box using: (a) VICONOPT; (b) VMULTI. Nodes in the upper skin are vertically above their counterparts in the lower skin, so the design variables apply to both skins. Breadths $b_{1}-b_{6}$ were the independent design variables and are shown thick. Corresponding breadths were design variables in the VMULTI option. Other breadths which were equal to the independent design variables are also labelled $b_{1}-b_{6}$ and the dependent breadths are denoted $x_{1}-x_{4}$. The dependency of $x_{1}-x_{4}$ on $b_{1}, b_{3}$ and $b_{6}$ was not sufficiently relevant to be defined in this paper. 